\title{
El problema sexual
}

\section{ENSEÑANZAS PARA LOS JOVENES}

Conferencia dictada en el aula magna del Liceo de Aplicación, y dedicada por el aufor a ATENEA.

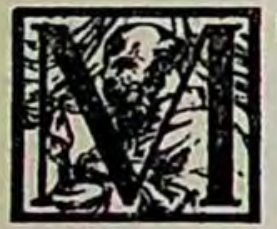

UCHO he meditado antes de abordar tan delicado problema: yo os debo respeto a vosotros y me lo debo a mí mismo. Pero ¿qué hacer? El problema de la vida sexual es de importancia superior. preocupa la atención de los jóvenes y de los viejos, de los maestros y de los gobiernos; ejerce sobre los sentimientos y el carácter una influencia preponderante. De su solución depende la felicidad o desgracia de la generación actual y de las futuras, el porvenir de la raza, de la patria, de la humanidad.

Cuando se halla sobre el tapete una cuestión de tales proporciones, callar obstinadamente, dejar a la juventud sin enseñanza, entregada a su propia suerte. sería la obra de un pudor mal entendido, sería un silencio culpable.

Leyendo una homilia de San Juan Crisóstomo, Padre de la Iglesia, encontré las siguientes palabras, que han sido para mi un poderoso estimulo en la tarea emprendida. Dice el Santo:

-Nosotros juzgamos absolutamente necesario dar a la juventud una enseñanza - seria, advertencias precisas y una prudente dirección en lo que se refiere a las

- cosas sexuales, como son necesarias las ennseñanzas y advertencias que se - le hacen sobre otras cuestiones importantes e igualmente peligrosas, en que no - es posible dejar a la juventud abandonada a sí misma y expuesta a los daños - que la amenazans.

Y por si alguien de los que me escuchan sintiera brotar en su corazón el sentimiento del pudor, le anticiparía que tal pudor es impudor, y le dirigiría las palabras que el mismo San Juan Crisóstomo trae en otra de sus homilías. Comentando aquella frase de San Pablo. Erunt duo in carne una. Serán dos en una carne, habla el Santo Doctor con cierta libertad de las relaciones conyugales, $y$, notando que enrojecen algunos de los oyentes, les dice: 
- Yo veo que algunos de vosotros enrojecen al escuchar mis palabras. ¿Y - por qué?. ¿he hablado por ventura de cosas vergonzosas? No, ciertamente. Lo - que he dicho es puro y santo. Que el matrimonio sea santo. que el lecho con- yugal permanezca sin mancha: tal es la enseñanza de San Pablo. Si alguno se - escandaliza, es porque no es casto.

Al abordar este problema, yo quiero colocarme en un terreno práctico.

Algunos de los que me escuchan rechazan como anticuada la moral cristiana; y si yo hablara en su nombre, mis palabras no llegarian a su conciencia, no alcanzarían, por tanto, su objetivo. Por eso, no me colocaré en el terreno de la moral cristiana.

Todos vosotros, ciertamente sin excepción, admitis los progresos y las ventajas de la civilización y estáis convencidos de que su existencia es cuestión de vida o muerte para la humanidad. Pues bien. descenderé a este terreno, y a la luz de la moral civilizada, estudiaré el problema sexual. Hablaré, pues, en nombre de principios que todos admitimos como útiles y dignos de respeto.

Yo no vengo a hablar a la imaginación, sino a la fría razón. No esperéis. pues, deleitar vuestros oídos con frases bien cortadas o atrayentes figuras literarias. para fecundar la mente con la verdad, es siempre preferible un lenguaje sencillo. claro y al alcance de todos. parecido a la mansa lluvia de invierno que dulcemente penetra y esponja la tierra, más bien que el lenguaje estruendoso, de grandes períodos, retumbantes frases y brillantes imágenes, muy semejantes a los truenos y relámpagos que acompañan a las grandes tormentas, buenas únicamente para perjudicar y destruir.

Y sin más preámbulos, entremos en materia.

Siendo el hombre un ser social, que no vive aislado. cada una de sus palabras o acciones repercute en sus semejantes, ejerciendo una influencia útil o funesta. Es necesario, entonces, que, al obrar, él tome en cuenta a la colectividad y busque el equilibrio entre los dos sentimientos fundamentales, inherentes a su naturaleza, el egoismo y el altruismo. La morai humana consiste precisamente en la armonia de estas dos tendencias.

En todo tiempo. cada pueblo ha tenido su moral, o sea, un conjunto de reglas destinadas a guiar la conducta de los hombres. Estas normas han variado según las épocas o las razas, pero. con el progreso de la civilización, ellas tienden a unificarse, y llegarán a formar un código. aceptado al menos por las razas superiores. 
¿Cuál es esta moral única que se diseña en el horizonte, como resultado del trabajo secular de la civilización humana?

Yo diviso dos principios aceptados ya por todos los hombres. El primero se refiere a la conciencia individual; el segundo, a la conciencia colectiva.

Primer principio: La moralidad del individuo, tomado aisladamente, consiste en obrar siempre, en todas partes, y a cualquier precio, obedeciendo a su conciencia, a sus intimas convicciones.

Es claro que una acción, en si misma, puede ser indeferente, útil o nociva, y como tal, aprobada o reprobada por los demás; pero, el que realiza la acción es moral o inmoral, según haya obrado conforme o disconforme con sus propias convicciones.

Pero, hallándose la conciencia individual sujeta a aberraciones, necesita de un censor, de un corrector, para hacer posible la vida social. Tan importante oficio lo desempeña la conciencia colectiva.

$\mathrm{Y}$ aqui cabe enunciar el segundo principio moral, aceptado por todos los hombres civilizados.

Segundo principio: La moralidad del individuo, considerado como miembro de la colectividad, consiste en obrar siempre, en todas partes, y a cualquier precio. consultando el mayor bien de su prójimo y de toda la colectividad.

No defenderé la infalibilidad de la conciencia colectiva. Durante largos siglos, ella ha sancionado cosas abominables, como la antropofagia, los sacrificios humanos, la esclavitud; y para no recurrir a la historia, os presentaré la más funesta de las aberraciones de hoy: la aprobación del asesinato internacional de la guerra.

Deseo que estas dos normas, o sea, los principios de moralidad individual y colectiva nos sirvan como hilos conductores en el laberinto que estamos por afrontar. Ellos nos proporcionan un criterio seguro en materias sexuales, criterio que debe aceptar y practicar todo hombre civilizado.

Todo lo que vive, planta o animal, vive con la condición de nutrirse y reproducirse. Estas dos condiciones están íntimamente unidas. $\mathrm{El}$ individuo crece gracias a la nutrición. cuando ha alcanzado su completo desarrollo. el excedente de nutrición constituye pequeñas partículas que, abandonando su organismo, están destinadas a desarrollarse y a fecundar nuevos seres, asegurando así la perpetuidad de la especie.

Los animales superiores se reproducen por germen. El germen macho se funde con el de la hembra, y de esta fusión-fecundación-nace la primera molécula viviente que se desarrolla y da la vida a un individuo de la misma especie.

Este individuo, en los primeros años de su existencia, no ofrece muchos caracteres distintivos del sexo, teniendo los órganos de la generación en estado muy rudimentario. Cuando el animal ha alcanzado su desarrollo, estos órganos 
se desarrollan a su vez, experimentando entonces el individuo la necesidad sexual.

Ahora bien, el hombre, en su juventud, o sea, antes de alcanzar su total desarrollo, se halla expuesto a un peligro del cual escapan los demás animales. De hecho, el animal joven no tiene idea alguna de la necesidad sexual: los animales adultos nada le enseñan; llega a su completo desarrollo sin saber que existe una necesidad sexual.

No sucede lo mismo con el hombre. Por desgracia, el lenguaje articulado se presta para fines indignos. El niño puede recibir, y recibe de hecho, lecciones funestas de un compañero más precoz o mayor que él, que le da a conocer antes de tiempo, no sólo los actos, sino también los vicios sexuales.

Los niños, que ni siquiera debían suponer estas cosas, se encuentran casi siempre al corriente de todo.

Por un fenómeno de reciprocidad, la parte moral obra sobre el físico y el físico sobre la moral.

La preocupación mental que se apodera del niño prematuramente instruído, obra sobre su parte física, hace afluir la sangre a los órganos de la generación, produciendo una madurez ficticia y el ficticio concepto de una necesidad que espontáneamente no se habria producido. La excitación de los órganos refuerza a su vez las ideas licenciosas: las imágenes obscenas asaltan el espíritu, preocupan la imaginación: de esto, al ejercicio prematuro de las funciones generadoras, no hay más que un paso.

Esta observación la consigna ya Rousseau en su _Emilio. Dice:

- Las enseñanzas de la Naturaleza son tardías y lentas; las de los hombres - son casi siempre prematuras y aceleradas. En el primer caso, los sentidos - despiertan a la imaginación; en el segundo. la imaginación es quien despierta - a los sentidos, dándoles una actividad precoz, que enerva y debilita por de - pronto a los individuos, y, a la larga, a la misma especie humana, (1). Y dejo a Rousseau.

Tales funciones realizadas antes de tiempo son fatales para el desarrollo del individuo, y producen la alteración de los mismos órganos, causando la ruina del poder generador.

El joven, entre nosotros, no alcanza su desarrollo completo antes de los veintidós años. Antes de llegar a esa edad, el joven no debe realizar ninguna función sexual, y si lo hace,_escuchadlo bien,-tendrá que lamentarlo con el tiempo.

La ruina ocasionada por el ejercicio prematuro de las funciones sexuales se produce más rápida y más profunda bajo la influencia de los vicios antinaturales.

Llegado el hombre a su madurez, se manifiesta en él la imperiosa necesidad sexual. ¿Qué hacer?

(1) Emilio:; IV, pág. 366. 
El animal se acerca a la primera hembra que encuentra: muchos hombres hacen lo mismo. Pero. si algunos se conducen como animales, esto no significa que su ejemplo sea digno de imitación.

El hombre civilizado se halla en la alternativa, o de satisfacer este deseo sexual como lo haría un animal cualquiera, o de refrenarse, por consideraciones que le dictan la razón y el sentimiento.

Por una parte, él reflexiona: LLa Naturaleza ha puesto en mítal deseo; yo lo puedo satisfacer. Todos hacen lo mismo: cpor qué he de ser yo una excepción?,

Por otra parte, él piensa en las consecuencias que pueden seguirse de tal acto, piensa en la mujer que algún día será su compañera; piensa que la civilización humana no existiria si la conducta de los demás justificase siempre nuestra propia conducta.

Se dice y repite con majadería que la salud exige la satisfacción de los deseos sexuales. Profundo error. Los animales domésticos o prisioneros, a los cuales no se permite el acceso a sus congéneres del otro sexo, no sufren por esto daño alguno. Según los especialistas, tal privación, en muchos casos, es favorable para los individuos, como sucede en los perros de caza y en los caballos de carrera. Y descendiendo a nuestra especie, es demasiado sabido que a los campeones atléticos se les somete durante su entrenamiento a una completa abstinencia sexual.

Oigamos al respecto la opinión de algunos hombres de ciencia.

El doctor Gay dice: La castidad antes del matrimonio y después, cuando es preciso, no solamente es posible, sino saludable desde todo punto de vista, (1).

El doctor Beale, profesor del Colegio Real de Londres, se expresa así: .Es absolutamente falsa y sin ningún fundamento cientifico la opinión de que los jóvenes que no pueden casarse pronto deban, por motivos de salud, buscar fuera del matrimonio lo que sólo es lícito dentro de él.

El doctor Forel, profesor de Psiquiatría de la Universidad de Zurich, escribe, refiriéndose a la abstinencia sexual: La salud no sufre con ella lo más minimo, (2).

Los males de la incontinencia, dice Surbled, son por desgracia harto conocidos y por nadie negados: pero los que dicen que produce la continencia son supuestos, imaginarios, (3).

Los especialistas en enfermedades venéreas, reunidos en Bruselas en Septiembre de 1902, firmaron la siguiente declaración: eEs necesario, por sobre todas las cosas, enseñar a los jóvenes que la continencia y la castidad no sola-

(1) De la Purefé Rationelle, pág. 15.

(2) La cuestión sexual, pág. 83.

(3) La morale dans ses rapports avec la medicine ef l' higiene, I, 50. 
mente no son perjudiciales, sino que deben ser especialmente recomendadas desde el punto de vista medicinal e higiénico. Ciento cincuenta eminencias cientificas pusieron su firma al pie de tal declaración, presentada por Neisser.

Los miembros de la Facultad de Medicina de Cristianía, por unanimidad, afirmaron lo siguiente: Ninguno de nosotros conoce una enfermedad o un sintoma de debilidad que podamos atribuir al hecho de llevar una vida moral y continentes. (Cit. p. E. Ernest. pág. 23).

En la Advertencia a los esfudiantes, circular firmada por los profesores de higiene de veinte universidades alemanas, se lee: -La experiencia de muchos siglos demuestra que la abstención o limitación de las relaciones sexuales no se oponen al desarrollo corporal o intelectual de la juventud.

$\mathrm{Y}$ antes de abandonar el terreno de las autoridades médicas mundiales. quiero reproducir la opinión de dos médicos nuestros, los doctores Sierra y Moore, prolesores de la Escuela de Medicina.

Dice el primero: Todo joven debería estar absolutamente persuadido de que la castidad, aun prolongada por muy largos años, es perfectamente compatible con la más perfecta salud. (1).

El doctor Moore. refiriéndose a un folleto sobre la continencia, escribe: .He tratado este delicado asunto, llegando a las mismas conclusiones que aceptan hoy todos los hombres dedicados a la cuestión sexual: que los solteros no necesitan de la vida sexual; que la continencia vigoriza, eleva los sentimientos morales y aleja en absoluto al hombre de peligros psíquicos, corporales y económicos... El hombre debe llegar casto a formar una nueva familia..

En una conferencia que dictó el mismo doctor en la Universidad de Concepción el 9 de Junio de 1923. dijo textualmente: ‘La ciencia ha probado que la continencia no enferma a nadie, y que iguales abstenciones deben tener los jóvenes, como las que exigen de las niñas antes del matrimonio, (2).

La declaración de principios de la Liga chilena de higiene social contiene la misma doctrina: .Todos pueden y deben ser castos, y no tener relaciones sexuales fuera del matrimonios.

La afirmación, pues, de que la salud exige el sacrificio de la castidad es tan sólo un pretexto para burlar el mandato que nos impone la sujeción del cuerpo a las leyes del espíritu. Y, por desgracia, no faltan médicos ignorantes que se hacen cómplices de tales pretextos. Cuando un joven le dice: - Me duele la cabeza, siento palpitaciones, no concilio el sueño, ellos no se preocupan de averiguar si el doliente bebe demasiado alcohol, té, café u otras bebidas exitantes: si fuma demasiado o lleva una vida sedentaria y antihigiénica. sino que le dan el consejo protocolar: Usted necesita mujers.

A tales médicos convendría recordarles lo que ha escrito el doctor Ziemann de Londres: . El médico que aconseja la vida sexual ilegitima comete un infame delito: podría aconsejar también el robo y el asesinatos.

(1) La salud nacional.

(2) Atenea, Junio de 1924. 
No creáis a esos galenos, jóvenes que me escucháis: la continencia es posible. No digo que sea lácil; muchas veces es penosa, lo que depende principalmenle de la constitución individual, de las circunstancias exteriores y del régimen de vida. En general, comemos demasiado, bebemos muchas sustancias exitantes. despreciamos las preocupaciones serias y nos dedicamos poco a los ejercicios físicos. La continencia difícil, dice Fonsegrives, es la de los ociosos y glotones. Nos es difícil también la castidad del cuerpo porque no poseemos la castidad del espíritu.

Sigamos al joven que ha recibido tan torpes consejos de un médico.

Supongamos que él sienta horror por las mujeres públicas, como no puede menos de experimentarlo cualquier espiritu medianamente bien puesto. ¿Qué haria? Procurará tener relaciones con una muchacha honesta y la seducirá. Una joven. querida de un hombre, está perdida para la sociedad. Pero hay algo más: esa muchacha va a ser madre.

Y el hombre de corazón ¿no deberá pensar en esa infeliz, arrojada probablemente de su hogar, quizás huésped de un hospital, quizás suicida, y no pocas veces asesina de su propio hijo? ¿Y después?; la cárcel si es sorprendida en su delito; la prostitución, si logra escapar de la justicia. Y si el hijo. si vuestro hijo vive ¿qué suerte correrá, sin padre, sin educación, sin alimentos, sin hogar?

El doctor Förster, profesor de Pedagogía de la Universidad de Zurich, refiere el caso de Ana Jurke, mujer de mala vida, cuya descendencia fué formada principalmente por mendigos y prostitutas.

Por cada seducción, por cada unión ilegítima, se corre el riesgo de arruinar a dos seres humanos por lo menos. Y esto ¿no dice nada a vuestra conciencia de jóvenes honrados?

Pero. no solamente hay dos desgraciados. La paz de vuestro futuro hogar se encuentra amenazada. Quizás la mujer por vosotros seducida se presentárá a vuestra joven esposa, para decirle, mostrando a una tierna creatura: de vuestro marido.

Quiero suponeros convencidos de la indignidad de seducir a una mujer.

.Sí, diréis, esto es cruel, es injusto; satisfaré mis apetitos en una mujer públicas.

Pero, dejadme preguntaros: ¿qué es una mujer pública? Es una seducida de ayer. Os hacéis, por lo tanto. cómplices del primer seductor, aprovecháis su delito y empujáis más al abismo a la víctima de su traición.

Los que son insensibles a estas consideraciones morales y afectivas, deben pensar en las enfermedades venéreas a que se exponen con el trato sexual ilegitimo. 
Todos conocen algo de estas enfermedades; pero son pocos los que tienen de su gravedad un conceplo aproximado. Debo anticipar que toda precaución es inútil. o, por lo menos, insuficiente, para evitar los peligros del trato sexual ilegítimo. En Chile, más que en Europa, son ilusorias las garantias de inmunidad.

Oíd a un médico inglés, refiriéndose a los servicios profilácticos de su pais: -No existe ninguna garantia de inmunidad para el que se exponga al contagio. creyendo que ciertos sitios no ofrecen peligro porque son inspeccionados. Entre nosotros. esos servicios sanitarios del ramo son de todo punto deficientes: a mi juicio. contraproducentes, porque tienden a inspirar confianza a tantos que se imaginan que bastan para evitar todo peligro.

Abraham Flexner, en su libro La prostifución en Europa, trae el siguiente dato: Sobre 1,177 mujeres con enfermedades venéreas, todas de mala vida, sometidas a curación en el hospital municipal de Zurich, sólo el $8 \%$ confesaron su oficio de mujeres públicas, el $7 \%$ declararon no tener ocupación; todas las otras, o sea, el $85 \%$ tenían empleos remunerativos.

En 1896, en Berlin, por cada mujer matriculada como prostituta, había 12 que ejercian el oficio clandestinamente, escapando a toda vigilancia sanitaria.

No quiero haceros reír con la pretensión de comparar nuestro estado sanitario y reglamentos municipales con los paises o ciudades europeas.

En Santiago, se puede afirmar con seguridad, en cada trato sexual ilegitimo, hay un $95 \%$ de probabilidades de tomar el contagio.

Dos enfermedades, de las llamadas sociales, preocuparán levemente nuestra atención: la gonorrea y la sifflis.

Aunque la gonorrea no es una enfermedad consfitucional, propiamente dicha, y permanezca local. salvo algunos casos en que se trasmite a otros órganos, no obstante. ella ocasiona al individuo. a su mujer y a sus hijos males bajo cierto aspecto 'tan fatales como los de las sífilis.

1. En el individuo. el microbio de la gonorrea (gonococo) no se destruye fácilmente. Muchas veces desaparece la faz aguda de la enfermedad, pero ella persiste en estado crónico, y algunas veces, incurable. Se producen con frecuencia graves inflamaciones, origen de tenaces sufrimientos, que hacen necesaria la intervención quirúrgica, no siempre coronada por el éxito. El gonococo suele difundirse en todos los órganos genitales, produciendo transtornos en el sistema nervioso y terminando casi siempre con la esterilidad de los individuos afectados.

2. ${ }^{\circ}$ Haciendo abstracción de la infección blenorrágica, inmediata y de la faz aguda de la enfermedad, muchas mujeres honestas son infestadas poco a poco por un marido blenorrágico crónico. El virus en este caso se presenta en forma ligera, pero crónica. Como en el hombre, el microbio abarca en la mujer todos los órganos sexuales. llegando en muchos casos a producir peritonitis y concluyendo con la esterilidad.

3. Durante el parto, el recién nacido está expuesto a contraer la enferme- 
dad de la madre, hallándose en peligro cierto de sufrir la infección de los ojos. Basta recordar que la mayor parte de las oftalmias infantiles y los casos de ceguera son de origen venéreo.

Tales son las consecuencias de la gonorrea, la más benigna de las enfermedades venéreas.

La sifilis es más grave y mucho más contagiosa. Ella puede comunicarse por cualquier contacto con el objeto infestado. Basta un beso, un apretón de manos, beber en una copa que haya usado un sifilitico, para tomar el contagio. Se conocen casos de individuos que se han contagiado por medio de la nariz. por haberse sonado después de estrechar la mano a un sifilitico (1).

-El sifilítico, dice Blanc y Benet, no sólo es peligroso por directo contagio. sino porque contamina cuanto está a su alcance y sirve para su uso: sus cucharas, vasos, boquillas, pipas, objetos de tocador; los lápices, plumas, instrumentos músicos, sopletes; hasta sus ropas son medios comunes de propagación.

¿Y cómo, me preguntaréis, las autoridades sanitarias, que obligan a los médicos a denunciar cualquier enfermedad contagiosa, dejan circular libremente a los que difunden esta enfermedad incurable y hereditaria.

Os responderé brevemente. Es uno de los numerosos ejemplos de la protección del vicio por medio del hombre.

Se comprende que los inocentes, infestado por el contagio de los culpables. llegan a ser a su vez centros de infección que ponen en peligro a cuantos los rodean.

El profesor Gebert presentó el siguiente caso en la sesión del 12 de Febrero de 1896, en la Sociedad de Medicina de Berlin:

Una mujer, madre de seis robustos hijos. fué reconocida como enferma de sífilis. Su esposo no tenía el mal; ella era honrada. ¿De dónde provenía esa sifilis? Por caridad, la pobre mujer había ofrecido el pecho al hijo de una vecina, tierna criatura que había contraído la enfermedad por el contacto con su hermana, novia de un muchacho sifilítico que le habia dado un beso. A más de la mujer en cuestión, fué infestado también otro recién nacido, por el uso del biberón de la criatura enferma.

$\mathrm{Y}$ todo por el beso de un novio.

La sifilis, lo he afirmado anteriormente, es incurable en muchos casos.

Con frecuencia desaparece y cicatriza el lugar primario de la infección. Pueden también desaparecer los accidentes secundarios, como los bubones. placas mucosas u otras erupciones. Pero, tarde o temprano, se revelan los accidentes terciarios. comienzan a manifestarse poco a poco los accidentes cuaternarios que pueden herir cualquier órgano, pero que escogen de preferencia el cerebro o la médula espinal.

El que ha sufrido, pues, una infección a los veinte años, experimenta sus consecuencias a los cuarenta y a los sesenta años, pasando por las diversas etapas

(1) Semaine Medicale, 1898. 
de tan tremenda enfermedad, que lo acompaña hasta el sepulcro, cumpliéndose asi en él las palabras de Job:

-Sus huesos se llenarán de los vicios de su juventud y con él dormirán en el polvo, (XXI, v. 11).

Pero aun no abordamos el aspecto más temible de la sifilis: ella es Hereditaria. Basta que uno de los padres sea sifilitico, para que los hijos también lo sean, en la generalidad de los casos.

Hay hombres que cometen el delito de casarse, hallándose enfermos, y hay otros, más infames todavía, que se infestan después del matrimonio.

Es necesario recordar que la herencia tiene un doble origen y que puede predominar en el hijo el factor paterno o materno. Por esto, el hijo de un sifilitico no es siempre sifilitico.

Cuando ha recibido el terrible virus el individuo muere en el seno de la madre, o nace prematuramente, o muere al nacer. Si sobrevive, tarde o temprano aparece la enfermedad.

¿Calculáis vosotros la angustia de ese hijo inocente cuando se da cuenta de que su vida sobre la tierra será un martirio. y esto, debido a la maldad de su padre?

El doctor Regis publicó hace años un trabajo sobre la parálisis infantil, en el que demuestra que casi todos los casos de esta enfermedad son originados por la sifilis hereditaria.

-La sifilis, dice el doctor Gay, mata a los niños antes del nacimiento, ya que predispone extraordinariamente al aborto. Mata a los niños después del nacimiento en una proporción colosal $(80 \%$, como término medio). Y los niños que sobreviven son seres decaídos, idiotas y raquíticos, que transmiten más tarde a sus hijos las taras que ellos mismos recibieron. (1).

Volvamos al contagio.

Si la madre logra escapar al confagio de su marido, infaliblemente se infestará al alimentar a su hijo.

Suponed que pechos mercenarios sustentan al recién nacido: suponed que jóvenes madres, ignorantes del peligro, prestan su pecho al hijo ajeno, para obtener una miserable retribución: ahí tenéis nuevas víctimas que, a su vez, contagiarán a sus hogares inocentes. Y sus hijos, al ir a la escuela, infestarán a sus compañeros, pudiendo alcanzar el contagio a una población entera.

Chile tendría ya muchos millones de habitantes si la sifilis no esterilizara los hogares ni asesinara a los niños.

Tales son las consecuencias materiales del trato sexual ilegitimo: ¿qué deciros de sus efectos intelectuales y morales?

Jóvenes estudiantes. os recordaré solamente que la luz de la inteligencia

(1) De la Pureté Rationelle, pág. 39. 
palidece, que el fuego de los nobles amores se extingue y que todas las aspiraciones e ideales sucumben al empuje de la pasión sexual, que todo lo reclama para sí, que todo lo arranca, que todo lo devora.

Yo querria, señores, ya que os he presentado algunas desastrosas consecuencias del trato sexual ilegítimo, ofreceros también sus remedios; pero la hora no nos permite seguir adelante en la tarea. Pueda ser que el cielo nos depare otra oportunidad para hacerlo.

Deberé, pues, terminar, aplicando los dos principios morales de que os hablé momentos atrás, al problema sexual que hemos venido resolviendo:

1. El modo de obrar de un individuo, como tal, no es moral si no es conforme a las convicciones intimas, relativas al bien y al mal.

Vosotros, señores, en el fondo de vuestro corazón, desaprobáis, ciertamente. la licencia sexual de los hombres, y aplaudis sin reservas al que sabe sobreponerse a las inclinaciones materiales. Obrad, entonces, de acuerdo con ese pensamiento interior, si queréis ser morales.

$2 .^{\circ} \mathrm{El}$ modo de obrar de un individuo, como miembro de la sociedad, sólo es moral cuando está conforme con el mayor bien de todos y de cada uno.

La prostitución masculina causa a la mujer, a la familia, a la patria, a la humanidad, perjuicios cuya extención y gravedad son incalculables. Si vosotros os entregáis al trato sexual ilegitimo, traicionáis este segundo principio moral que admite todo hombre civilizado, os colocáis en pugna con vuestra conciencia de miembros sociales, os haceeis acreedores al titulo de viles e inmorales.

Dios y la patria, la salud del cuerpo y el vigor del espíritu, la justicia y la caballerosidad, os imponen estos dos preceptos que resumen la moral sexual y que vosotros jamás debéis olvidar:

1. Respetad la mujer, la hermana y la hija de ofro. como queréis que se respefen las vuestras.

2. ${ }^{\circ}$ Sed castos para que seáis fuertes, y con el tiempo tengáis hijos vigorosos de alma y cuerpo, consuelo y sostén de vosotros y ejemplares selectos de la especie.

He dicho. 